\title{
Critical Care for Patients with Massive Ischemic Stroke
}

\author{
Sang-Beom Jeon, ${ }^{a}$ Younsuck Koh, ${ }^{b}$ H. Alex Choi, ${ }^{c}$ Kiwon Lee ${ }^{c}$ \\ ${ }^{a}$ Department of Neurology, Asan Medical Center, University of Ulsan College of Medicine, Seoul, Korea \\ ${ }^{b}$ Department of Pulmonary and Critical Care Medicine, Asan Medical Center, University of Ulsan College of Medicine, Seoul, Korea \\ 'Departments of Neurology and Neurosurgery, The University of Texas Medical School at Houston, Houston, Texas, USA
}

Malignant cerebral edema following ischemic stroke is life threatening, as it can cause inadequate blood flow and perfusion leading to irreversible tissue hypoxia and metabolic crisis. Increased intracranial pressure and brain shift can cause herniation syndrome and finally brain death. Multiple randomized clinical trials have shown that preemptive decompressive hemicraniectomy effectively reduces mortality and morbidity in patients with malignant middle cerebral artery infarction. Another life-saving decompressive surgery is suboccipital craniectomy for patients with brainstem compression by edematous cerebellar infarction. In addition to decompressive surgery, cerebrospinal fluid drainage by ventriculostomy should be considered for patients with acute hydrocephalus following stroke. Medical treatment begins with sedation, analgesia, and general measures including ventilatory support, head elevation, maintaining a neutral neck position, and avoiding conditions associated with intracranial hypertension. Optimization of cerebral perfusion pressure and reduction of intracranial pressure should always be pursued simultaneously. Osmotherapy with mannitol is the standard treatment for intracranial hypertension, but hypertonic saline is also an effective alternative. Therapeutic hypothermia may also be considered for treatment of brain edema and intracranial hypertension, but its neuroprotective effects have not been demonstrated in stroke. Barbiturate coma therapy has been used to reduce metabolic demand, but has become less popular because of its systemic adverse effects. Furthermore, general medical care is critical because of the complex interactions between the brain and other organ systems. Some challenging aspects of critical care, including ventilator support, sedation and analgesia, and performing neurological examinations in the setting of a minimal stimulation protocol, are addressed in this review.

Keywords Critical care; Stroke; Coma
Correspondence: Sang-Beom Jeon Department of Neurology, Asan Medical Center, University of Ulsan College of Medicine, 88 Olympic-ro 43-gil, Songpagu, Seoul 138-736, Korea

Tel: $+82-2-3010-3440$

Fax: +82-2-474-4691

E-mail: sbjeonmd@gmail.com

Received: June 27, 2014

Revised: September 3, 2014

Accepted: September 4, 2014

The authors have no financial conflicts of interest.

\section{Introduction}

Malignant cerebral edema following ischemic stroke is life threatening. The pathophysiology of brain edema involves failure of the sodium-potassium adenosine triphosphatase pump and disruption of the blood-brain barrier, leading to cytotoxic edema and cellular death. ${ }^{1}$ The Monro-Kellie doctrine dictates that since the brain is encased in a finite space, increased intracranial pressure (ICP) due to cerebral edema can result in herniation through the foramen magnum and openings formed by the falx and tentorium. ${ }^{2}$ Moreover, elevated ICP can cause secondary brain ischemia through decreased cerebral perfusion and blood flow, brain tissue hypoxia, and metabolic crisis. ${ }^{3} \mathrm{Di}-$ rect cerebrovascular compression caused by brain tissue shifting 
can lead to secondary infarction, especially in the territories of the anterior and posterior cerebral artery. ${ }^{4}$ Tissue shifts can also stretch and tear cerebral vessels, causing intracranial hemorrhage such as Duret's hemorrhage of the brainstem. ${ }^{4}$ Physicians treating ischemic stroke with swelling should utilize every available medical and surgical therapy to minimize secondary brain injuries. Therefore, patients with space-occupying ischemic stroke are advised to be admitted to an intensive care unit (ICU) for constant neurological monitoring. ${ }^{5}$

Physicians who manage stroke patients should try to understand the body as a whole and not be limited to the brain. It is possible that provision of comprehensive care is the critical factor that determines patient outcomes, rather than focusing on one specific therapy. However, managing the brain and the rest of the body simultaneously presents a challenge to the physician, as focusing on one organ may be at the cost of another.

In this review, we provide a comprehensive overview of the management of cerebral and cerebellar infarction with malignant edema. We discuss the measurement of ICP and strategies to lower ICP, including decompressive craniectomy and therapeutic hypothermia. Finally, we discuss ventilatory support and the advantages and limitations of a sedation-off wake-up test.

\section{Measurement of ICP}

ICP is the pressure exerted by the brain, blood, and cerebrospinal fluid (CSF) in the intracranial vault. The skull is a rigid container filled with the brain, blood, and CSF. Expansion of one component occurs at the expense of others, with increases in ICP leading to intracranial hypertension. Normal ICP values for adults are 7-15 mmHg. ${ }^{6}$ Generally, ICP values greater than $20 \mathrm{mmHg}$ require treatment. ${ }^{7}$ However, ICP should be interpreted in the context of cerebral perfusion pressure (CPP). CPP is a major factor that affects cerebral blood flow $(\mathrm{CBF})$. It is determined by calculating the difference between mean arterial pressure (MAP) and ICP (CPP = MAP-ICP). CPP can therefore decrease as a result of decreased MAP, increased ICP, or a combination of both. CPP is proportional to $\mathrm{CBF}$ as long as cerebrovascular resistance remains constant. To avoid secondary brain ischemia after stroke, extremely low CPP should be avoided. Optimal CPP values have not been clearly established, but $50-60 \mathrm{mmHg}$ is generally accepted as the minimum pressure required to prevent further brain injury. ${ }^{3}$

The gold standard assessment of ICP requires insertion of an extraventricular drain (EVD) into the lateral ventricle with a connection to an external pressure transducer. ${ }^{8}$ In addition to monitoring absolute pressure values and waveforms, an EVD catheter allows CSF diversion to reduce ICP. Alternatively, ICP can be measured through intraparenchymal, transducer-tipped catheters, including fiber optic and microstrain-gauge sensors. ${ }^{8}$ A parenchymal catheter can provide continuous measurement of ICP and allows analysis of the interaction between ICP and MAP (pressure reactivity index) as well as real-time values and ICP waveforms. ${ }^{9}$ Although this device provides a quantitative value for ICP, it can only be calibrated prior to placement of an ICP probe and is vulnerable to drift.

There are controversies surrounding ICP monitoring in patients with stroke. Early studies showed that ICP monitoring was useful for predicting clinical outcomes after acute hemispheric stroke. ICP often correlated with clinical deterioration, final outcome, and computed tomography findings. ${ }^{10}$ However, a subsequent study of patients with malignant middle cerebral artery (MCA) infarctions showed that pupillary abnormalities and signs of severe brainstem compression were sometimes present despite normal ICP. ${ }^{11}$ Randomized clinical trials of ICP monitoring have not been performed in patients with stroke. A randomized clinical trial of ICP monitoring in patients with traumatic brain injury failed to show superior efficacy of ICP monitoring over serial neurological examinations and repeated neuroimaging studies. ${ }^{12}$ Limitations of ICP monitoring in predicting neurological deterioration may be due to the distance between the site of ICP probe insertion and the site of herniation (Figure 1A), because the pressure gradient force is inversely proportional to the distance. The relative positioning of the tentorial aperture and the brainstem may also explain variations in herniation syndromes in patients with similar ICP values and intracranial pathological conditions. Some patients exhibit a narrow tentorial opening and a high degree of contiguity between the brainstem and the tentorial edge, whereas others exhibit a wide tentorial opening and perimesencephalic space. Such morphometric variations in the tentorial aperture and its regional anatomy may play a role in the varying clinical manifestations (Figure 1B).${ }^{13}$ Alternatively, since the brain has compartments divided by hard dural structures, i.e., the falx cerebri and tentorium cerebelli, ICP probes placed in the right frontal cortex may not appropriately reflect the pressure in the left hemisphere or infratentorium (compartmentalized ICP). ${ }^{10,14}$ Malfunction of a mechanical device and probe drift may also contribute to inaccurate ICP values. Therefore, routine ICP monitoring without careful interpretation, neurological examination, and a neuroimaging study cannot be recommended in patients with cerebral and cerebellar infarct with swelling. ${ }^{5}$ However, it may be helpful in comatose patients especially during barbiturate coma therapy and ventilator care under heavy sedation because in these situations neurological examinations are not sensitive enough to detect secondary brain injury, and constant neuroimaging 

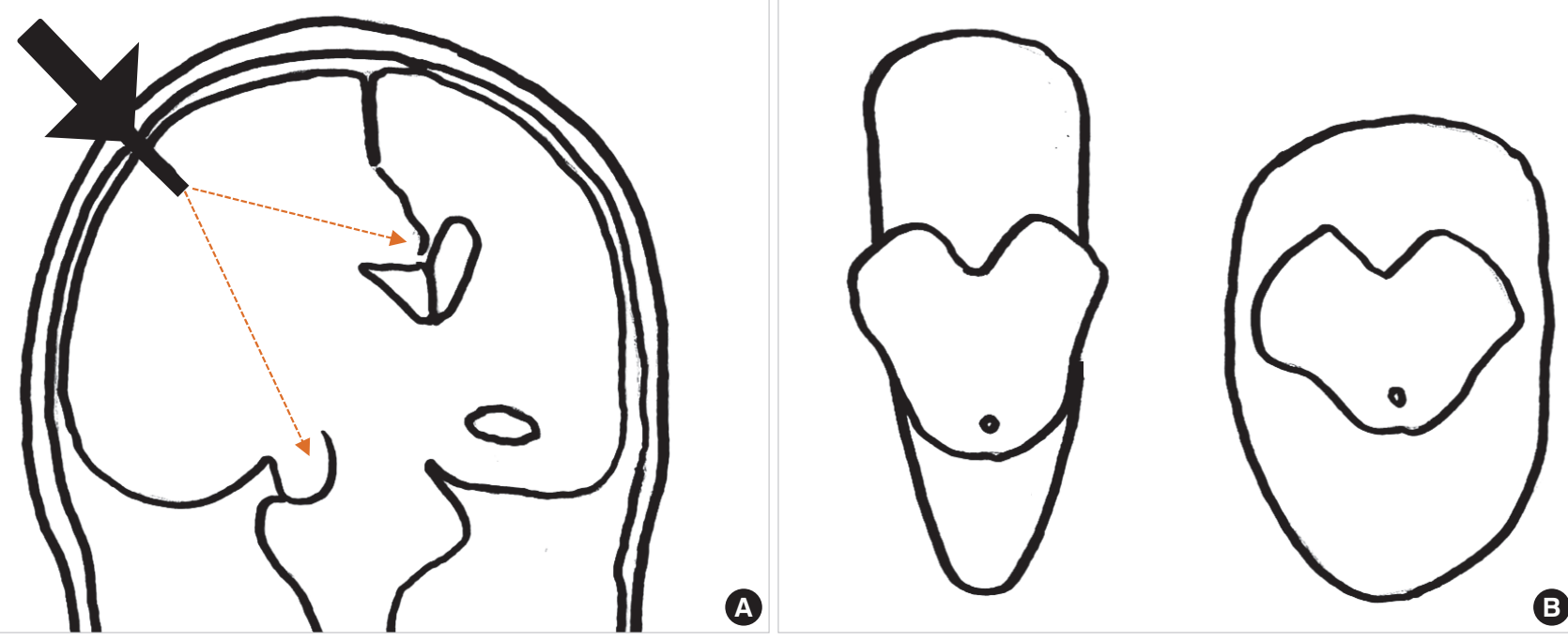

Figure 1. Measurement of ICP and herniation. (A) The distance (orange lines) from the ICP probe (black arrow) to the herniation site may contribute to the discrepancy between measured ICP and clinical deterioration. (B) Variations in the morphometric relationship between the tentorial aperture and the brainstem. Note the differences between the brainstem and the tentorial notches. The patient on the left is more susceptible to herniation syndromes and Kernohan's notch than the one on the right.

studies are not available. Multimodal neuromonitoring that includes ICP, CPP, CBF, brain oxygen tension, markers of brain metabolism (glucose, lactate, and pyruvate) and electroencephalography may be useful to further understand the physiology of comatose stroke patients. ${ }^{15}$

\section{Medical management of intracranial hypertension}

In general, there are four causes of intracranial hypertension following ischemic stroke: (1) brain swelling due to cytotoxic or vasogenic edema; (2) increased cerebral blood volume due to dilated cerebral arteries; (3) obstruction of venous outflow; and (4) acute hydrocephalus. ${ }^{16}$ The optimal approach to manage intracranial hypertension differs according to the underlying cause. Brain swelling requires osmotherapy and/or decompressive craniectomy, cerebral arterial dilatation requires a vasoconstriction stimulus such as hyperventilation, obstruction of venous outflow requires a revision of head position and loosening of tube ties (in cases not complicated by venous sinus thrombosis), and acute hydrocephalus can be managed with CSF drainage through an EVD. ${ }^{16}$

Our stepwise protocol for controlling ICP is outlined in Table 1. It starts with consideration of decompressive craniectomy and CSF drainage through an EVD because these are the most effective measures for ICP control. ${ }^{17}$ Details on these surgical options are described in subsequent sections.
Table 1. Protocol for increased intracranial pressure ${ }^{\dagger}$

Stepwise management
A. Consideration of surgical decompression and/or drainage of cerebrospinal fluid.
B. General management
a. Mechanical ventilation after rapid sequence intubation
b. Head elevation to $30^{\circ}$
c. Neutral neck position and avoidance of constricting tube ties
d. Avoidance of hypoxia, hypercapnia, and hyponatremia
e. Control of fever and hyperglycemia
f. Treat seizures and use prophylactic anticonvulsants when appropriate
C. Sedation and analgesia
D. Hyperventilation: PaCO $230-35 \mathrm{mmHg}$ (or $25-30$ mmHg)
E. Optimization of cerebral perfusion pressure: intracranial pressure $\leq 20 \mathrm{mmHg}$
and cerebral perfusion pressure $\geq 60 \mathrm{mmHg}$ (individualized)
F. Osmotherapy: mannitol or hypertonic saline
G. Therapeutic hypothermia
H. Barbiturate coma therapy

${ }^{\dagger}$ Modified from The NeurolCU Book. ${ }^{19}$ Consider as a rescue therapy, especially before emergent surgical decompression or initiation of other remedies.

\section{General management}

Assessment and management of the airway, breathing, and circulation is the initial step for treating increased ICP in unconscious stroke patients. Early rapid sequence intubation (RSI) should be considered for patients with comatose mental status and intracranial hypertension, and endotracheal intubation should be performed with medications to blunt any increase in ICP. Details on intubation, ventilatory support, and sedation are described in subsequent sections. Hypoxia and hypotension should be avoided during or after the procedure. Head elevation to $30^{\circ}$ has been shown to reduce ICP, although this can be accompa- 
nied by a decrease in CPP that offsets the beneficial effects. ${ }^{18}$ The head should be maintained in a midline position and tight ties around the neck should be avoided to improve jugular venous drainage. Other general measures to treat intracranial hypertension include avoiding hypoxia, hypercapnia and hypotonic conditions, controlling fever and hyperglycemia, and treating seizures. Details on ventilatory support and the strategy for sedation and analgesia are described in subsequent sections.

\section{Hyperventilation}

Decreasing $\mathrm{PaCO}_{2}$ to $30-35 \mathrm{mmHg}$ is an effective and rapid means to reduce ICP. A decrease in $\mathrm{PaCO}_{2}$ causes vasoconstriction, which lowers cerebral blood volume and thus lowers ICP. The effect is almost immediate but generally lasts only a few hours because the $\mathrm{pH}$ of CSF rapidly equilibrates to the new $\mathrm{PaCO}_{2}$ level. ${ }^{3}$ However, the effect of hyperventilation may be sustained for days in patients with excessive vasodilation and cerebral hyperemia. ${ }^{19}$ Prolonged, aggressive hyperventilation can cause cerebral ischemia in patients with brain injury, ${ }^{20}$ and the routine application of extreme hyperventilation is therefore generally considered harmful. Thus, the use of hyperventilation is best reserved for temporary, rescue therapy for sudden increases in ICP. It is not recommended to routinely hyperventilate patients for many hours or days.

\section{CPP optimization}

The minimal CPP required to prevent brain ischemia is generally accepted as $50-60 \mathrm{mmHg} .{ }^{3}$ However, there are two different approaches to whether CPP should be maintained at a higher or lower level. The Rosner concept advocates increasing MAP and targeting a higher $\mathrm{CPP}$ to maintain adequate $\mathrm{CBF},{ }^{21}$ whereas the Lund concept advocates decreasing resistance and intravascular hydrostatic pressure, and reducing cerebral blood volume, thereby increasing $\mathrm{CBF}$ and accepting a lower $\mathrm{CPP} .{ }^{22} \mathrm{Re}-$ cently, new approaches to individualize optimal CPP using multimodal neuromonitoring measures and statistics from these measures, such as the pressure reactivity index that is calculated using the moving correlation coefficient between ICP and MAP and the oxygen reactivity index that is calculated using the moving correlation coefficient between CPP and brain tissue oxygen, have been introduced. ${ }^{9,23}$ Details on different conceptual approaches are beyond the scope of this review.

\section{Osmotherapy}

Mannitol has been the cornerstone of osmotherapy for the treatment of intracranial hypertension. However, optimal usage of mannitol for stroke patients is uncertain. Usually, this drug is administered intravenously at a dose of $0.25-2.0 \mathrm{~g} / \mathrm{kg}$ per require- ment or every 6 hours. Serum osmolality up to $360 \mathrm{mOsm} / \mathrm{kg}$ can be tolerated. ${ }^{3}$ During osmotherapy with mannitol, it is crucial to maintain a hyperosmotic euvolemic state through adequate fluid balance. If not, the patient could suffer various adverse effects including dehydration, hypovolemia, hypotension, increased ICP, and decreased CPP, in addition to acute kidney injury and electrolyte imbalance. When mannitol needs to be discontinued after repeated use for several days, potential rebound increases in ICP should be monitored with consideration of mannitol tapering. Therapeutic drug monitoring for mannitol is unavailable in most hospitals, but physicians can use the osmolar gap, i.e., the difference between measured serum osmolality and calculated serum osmolarity, as an indirect indicator of serum mannitol levels. There are several approaches to calculate serum osmolarity, but the most simple, frequently used formula is as follows: serum osmolarity $=(2 \times \mathrm{Na})+($ gluco se/18)+(blood urea nitrogen/2.8). The osmolar gap correlates better than serum osmolality with the serum concentration of mannitol. ${ }^{24}$ When the osmolar gap is higher than $20 \mathrm{mOsm} / \mathrm{L}$, mannitol is generally withheld to avoid accumulation in the brain and circulation. ${ }^{3}$ However, $55 \mathrm{mOsm} / \mathrm{L}$ has also been suggested as a threshold value. ${ }^{25}$

Hypertonic saline is an alternative to mannitol for osmotherapy for intracranial hypertension. Although hypertonic saline provides an osmotic effect similar to mannitol, it has a better reflection coefficient (1.0) than mannitol (0.9), and is therefore less able to cross the blood-brain barrier and may have a stronger osmotic effect. Additionally, hypertonic saline normalizes resting membrane potential and has an anti-inflammatory effect. In existing reports, the concentration of hypertonic saline used to treat intracranial hypertension was $1.7 \%-30 \%$. A recent meta-analysis of five clinical trials showed greater ICP control with hypertonic saline than with mannitol in patients with traumatic brain injury (odds ratio, 1.16; 95\% confidence interval, 1.00-1.33).$^{17}$ Another recent meta-analysis of six studies showed that the percent decrease in ICP from baseline to either $60 \mathrm{~min}$ utes or the nadir after administration of $23.4 \%$ saline was $55.6 \%$ (standard error, 5.90; 95\% confidence interval, 43.99-67.12). ${ }^{26}$ Possible adverse effects of hypertonic saline are rebound cerebral edema, hyperchloremic metabolic acidosis, phlebitis, congestive heart failure, transient hypotension, hemolysis, hypokalemia, renal failure, osmotic demyelination, subdural hemorrhage, seizures, and muscle twitching. ${ }^{27}$ Various methods have been used to administer hypertonic saline. At the Asan Medical Center, a $60-120 \mathrm{~mL}$ dose of $11.7 \%$ saline, the highest available osmolar agent in Korea, is administered over 10-20 minutes via a peripherally inserted central catheter as required or every 6 hours. Serum sodium levels up to $155-160 \mathrm{mEq} / \mathrm{L}$ are typically 
well tolerated.

\section{Barbiturate coma therapy}

Barbiturate coma therapy is reserved for patients with refractory intracranial hypertension and can be delivered using pentobarbital or thiopental. ${ }^{28}$ These drugs are titrated on the basis of ICP measurements and continuous electroencephalogram monitoring. Pentobarbital is administered at a loading dose of 5 $\mathrm{mg} / \mathrm{kg}$ over $15-30$ minutes (up to $50 \mathrm{mg} / \mathrm{min}$ ) and then continuously infused at $1-5 \mathrm{mg} / \mathrm{kg} / \mathrm{h}$. Barbiturate coma therapy requires electroencephalograms to be continuously recorded and the barbiturate titration usually targets a burst-suppression pattern with approximately 6-8 seconds interbursts. ${ }^{19}$ Side effects of pentobarbital and thiopental include hypotension, myocardial suppression, respiratory suppression, infections, hepatic and renal dysfunction, thrombocytopenia, metabolic acidosis and gastric stasis. However, randomized clinical trials on the effect of barbiturate therapy for uncontrolled ICP have not been performed in stroke patients. Barbiturate coma therapy is the last resort for treatment of refractory intracranial hypertension due to a lack of sufficient evidence and various systemic side effects associated with it, including cardiac depression, arterial hypotension, and increased risk of infection. ${ }^{29}$

\section{Surgical management of brain swelling}

Medical management of brain edema and increased ICP may not be successful when significant swelling occurs in the cerebral or cerebellar hemisphere. Therefore, a decompressive craniectomy should be considered to relieve the mass effect of the swollen cerebral or cerebellar hemisphere on the thalamus, brainstem, and network projections to the cortex, manifested predominantly by decreased levels of arousal. ${ }^{5}$

\section{Malignant MCA infarction}

Malignant MCA infarction was originally defined as an acute infarction in the entire MCA territory evident on a computed tomography scan within the first 48 hours after symptom onset, with or without involvement of other vascular (anterior or posterior cerebral artery) territories. ${ }^{30}$ Subsequently, the term has been used to refer to large hemispheric infarcts that have occurred as a result of occlusion of the proximal MCA or internal carotid artery, with variable definitions (e.g., National Institutes of Health Stroke Scale score $\geq 15-20$; brain computed tomography ischemic signs involving $>50 \%-66 \%$ of the MCA territory; and diffusion-weighted imaging infarct volume $\left.>145 \mathrm{~cm}^{3}\right) .{ }^{31-35}$ Malignant MCA infarction accounts for approximately $5 \%$ of ischemic strokes and is most commonly caused by cardioembo- lism. ${ }^{30,36}$ Despite the best medical treatment, most patients deteriorate between post-ictus days 2 and 5, and malignant MCA infarction is characterized by severe morbidity and high mortality. ${ }^{30,37}$ Mortality ranges up to $70 \%-80 \%$ with medical treatment. ${ }^{38}$ For patients who present outside thrombolysis time windows or who already have areas of marked low density on computed tomography scans, treatment should aim to minimize brain swelling and control ICP. Among the variety of treatment modalities available to treat an increase in ICP, the most effective method is decompressive hemicraniectomy. ${ }^{17}$ In a meta-analysis of studies into the control of increased ICP, decompressive hemicraniectomy was found to cause a $19 \mathrm{mmHg}$ mean reduction in pressure, which was superior to the reduction in ICP seen with the use of hyperventilation $(6 \mathrm{mmHg})$, mannitol (8 $\mathrm{mmHg})$, barbiturates $(8 \mathrm{mmHg})$, hypothermia $(10 \mathrm{mmHg})$, hypertonic saline $(15 \mathrm{mmHg})$, or CSF drainage $(15 \mathrm{mmHg}){ }^{17}$

In decompressive hemicraniectomy, a bone flap over the frontal, temporal, parietal, and occipital lobe at the site of the infarct is removed, allowing the swollen brain tissue to expand extracranially (Figure 2). Decompressive hemicraniectomy with duroplasty can relieve horizontal and vertical tissue shifts, reduce ICP, improve CPP, and CBF, and alleviate vascular compression. During the last decade, several randomized clinical trials have shown that this procedure is most effective when performed within 48 hours post-ictus (Table 2). ${ }^{31-34}$ A hemicraniectomy performed too soon after ictus may result in unnecessary surgical procedures and complications, whereas a hemicraniectomy performed after herniation signs are fully developed may be of little value. Multiple randomized clinical trials have investigated if early ( $<48$ hours post-ictus) hemicraniectomy improves clinical outcomes for patients with malignant MCA infarction. Trials included young patients (age $\leq 60$ years) with severe symptoms (National Institutes of Health Stroke Scale score $\geq 20$ for the dominant hemisphere and $\geq 15$ for the nondominant hemisphere) and a decreased level of consciousness (score $\geq 1$ on item 1a of the National Institutes of Health Stroke Scale score or a gradual decrease in consciousness to a score $\leq 13$ on the Glasgow coma scale for right-sided lesions or $\leq 9$ for left-sided lesions). In a pooled analysis of three European trials, the number needed to treat for survival at 1 year was two and the number needed to treat for independent walking (modified Rankin Scale (mRS) score $\leq 3$ ) was four. ${ }^{33}$

Despite unequivocal effects on survival, there has been criticism that hemicraniectomy can barely avert death to a vegetative or minimally conscious state. However, patients with malignant MCA infarctions who may have been in a vegetative state (mRS score $=5)$ without hemicraniectomy could walk with some help $(\mathrm{mRS}=4)$ after hemicraniectomy. A recent meta- 

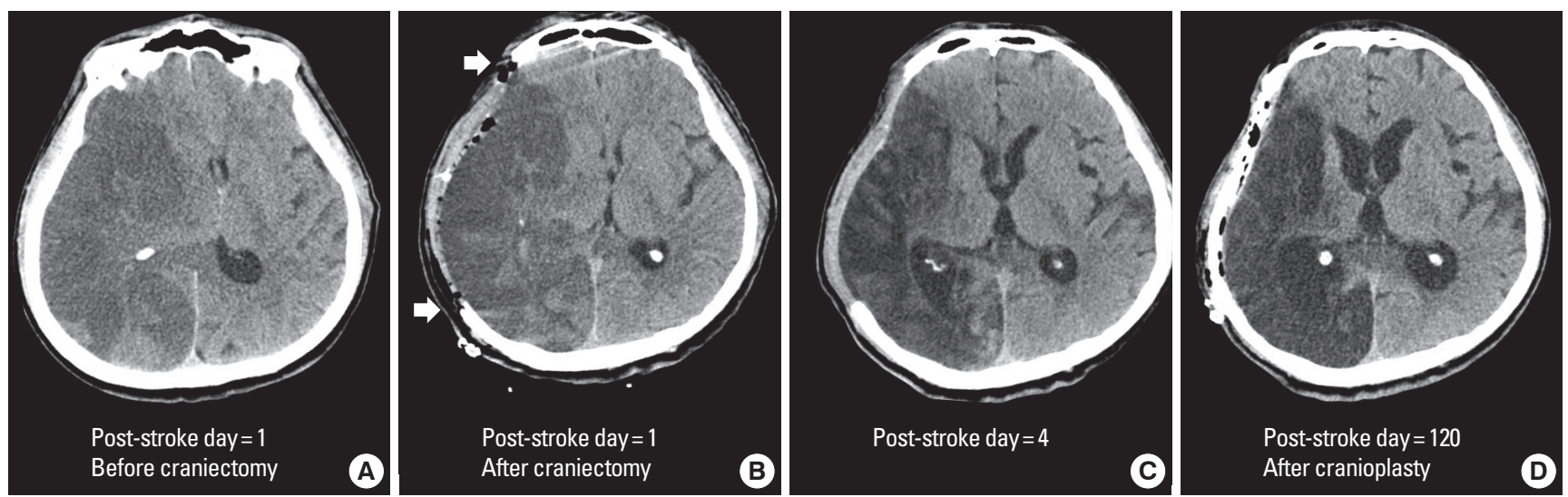

Figure 2. Decompressive hemicraniectomy for malignant MCA infarction. Computed tomography images from a 63-years-old male with atrial fibrillation and hypertension who presented with left-sided weakness. Images were obtained pre- $(\mathrm{A})$ and post- $(\mathrm{B})$ hemicraniectomy on post-stroke day 1, on post-stroke day $4(\mathrm{C})$ and post-cranioplasty on post-stroke day 120 (D). The day after symptom onset, the patient became drowsy and his right pupil dilated. He recovered alertness and pupillary isocoria hours after the decompressive hemicraniectomy. Brain computed topography performed 3 days after the hemicraniectomy did not show a midline shift (C) and the patient was transferred to the general ward. Cranioplasty was performed 4 months after the hemicraniectomy.

Table 2. Randomized clinical trials of decompressive hemicraniectomy for malignant middle cerebral artery infarction

\begin{tabular}{|c|c|c|c|c|c|c|c|}
\hline & \multirow{2}{*}{$\begin{array}{c}\text { Age } \\
\text { (years) }\end{array}$} & \multicolumn{2}{|c|}{ Survival } & \multicolumn{2}{|c|}{ Good outcome at 6 months } & \multicolumn{2}{|c|}{ Good outcome at 12 months } \\
\hline & & Surgical arm & Medical arm & Surgical arm & Medical arm & Surgical arm & Medical arm \\
\hline $\operatorname{DECIMAL}(n=38)^{31}$ & $18-55$ & $75 \%$ (30 days) & $22 \%$ (30 days) & $25 \%$ (mRS 2-3) & $5.6 \%(m R S 2-3)$ & $50 \%$ (mRS 2-3) & $22 \%$ (mRS 2-3) \\
\hline DESTINY $(n=32)^{32}$ & $18-60$ & $72 \%$ (1 year) & $47 \%$ (1 year) & $47 \%$ (mRS 2-3) & $27 \%$ (mRS 2-3) & $48 \%$ (mRS 2-3) & $27 \%$ (mRS 2-3) \\
\hline Pooled analysis $(n=93)^{33}$ & $18-60$ & $78 \%$ (1 year) & 29\% (1 year) & ns & ns & $75 \%$ (mRS 2-4) & $24 \%$ (mRS 2-4) \\
\hline HAMLET $(n=64)^{34}$ & $18-60$ & $84 \%$ (14 days) & $44 \%$ (14 days) & ns & ns & $25 \%$ (mRS 2-3) & $25 \%$ (mRS 2-3) \\
\hline DESTINY $\|(n=112)^{35}$ & $\geq 61$ & $67 \%$ (180 days) & $30 \%$ (180 days) & $39 \%$ (mRS 3-4) & $18 \%$ (mRS 3-4) & $38 \%$ (mRS 3-4) & $16 \%$ (mRS 3-4) \\
\hline
\end{tabular}

ns, not specified; mRS, modified Rankin Scale.

analysis showed that the vast majority of patients who underwent hemicraniectomy and their caregivers were satisfied with the outcome of surgery and would provide consent again for the procedure despite the high rate of physical disability and depression. ${ }^{39}$ Patients with an infarct in the dominant hemisphere may have a lower quality of life than patients with an infarct in the nondominant hemisphere because they have more severe language impairment. However, a meta-analysis found no differences in functional outcome between right- and left-hemispheric infarcts. ${ }^{40}$

Until recently, the efficacy of decompressive hemicraniectomy in patients 60 years of age or older has been uncertain. A recent randomized clinical trial showed that malignant MCA infarction patients aged $>60$ years who were treated with early ( $<48$ hours post-ictus) hemicraniectomy had a higher survival rate and better functional outcome than patients who were managed conservatively (Table 2). ${ }^{35}$ Thus, old age per se should not be regarded as an exclusion criterion for hemicraniectomy after malignant MCA infarction. Preemptive decompressive hemicraniectomy is an effective treatment for brain swelling in patients with malignant MCA infarction.

\section{Cerebellar infarction}

A space-occupying cerebellar infarct may cause brain death through brainstem compression and obstructive hydrocephalus. Large infarct size on initial magnetic resonance images, mostly in the territories of the posterior inferior cerebellar artery and superior cerebellar artery rather than the anterior inferior cerebellar artery, can suggest poor prognosis. ${ }^{41}$ Consciousness typically deteriorates between post-ictus days 2 and $4,{ }^{42}$ and surgical options should be considered when maximal medical therapy is failing.

One surgical option for treating a space-occupying cerebellar infarct is a suboccipital craniectomy, where the skull is removed and the dura expanded to relieve ICP caused by the swollen brain tissue (Figure 3). Although the efficacy of suboccipital craniectomy has been reported in observational and retrospective studies, ${ }^{42-44}$ no randomized clinical trials have been performed to test the efficacy of this procedure. The value of preemptive surgery (early surgery based on radiological findings such as cerebellar edema and hydrocephalus in a clinically stable patient) and the best neurosurgical approach (removal of necrotic tissue vs. decompression alone vs. decompression plus ventriculostomy) are unknown. ${ }^{5,45,46}$ In patients with acute hydroceph- 

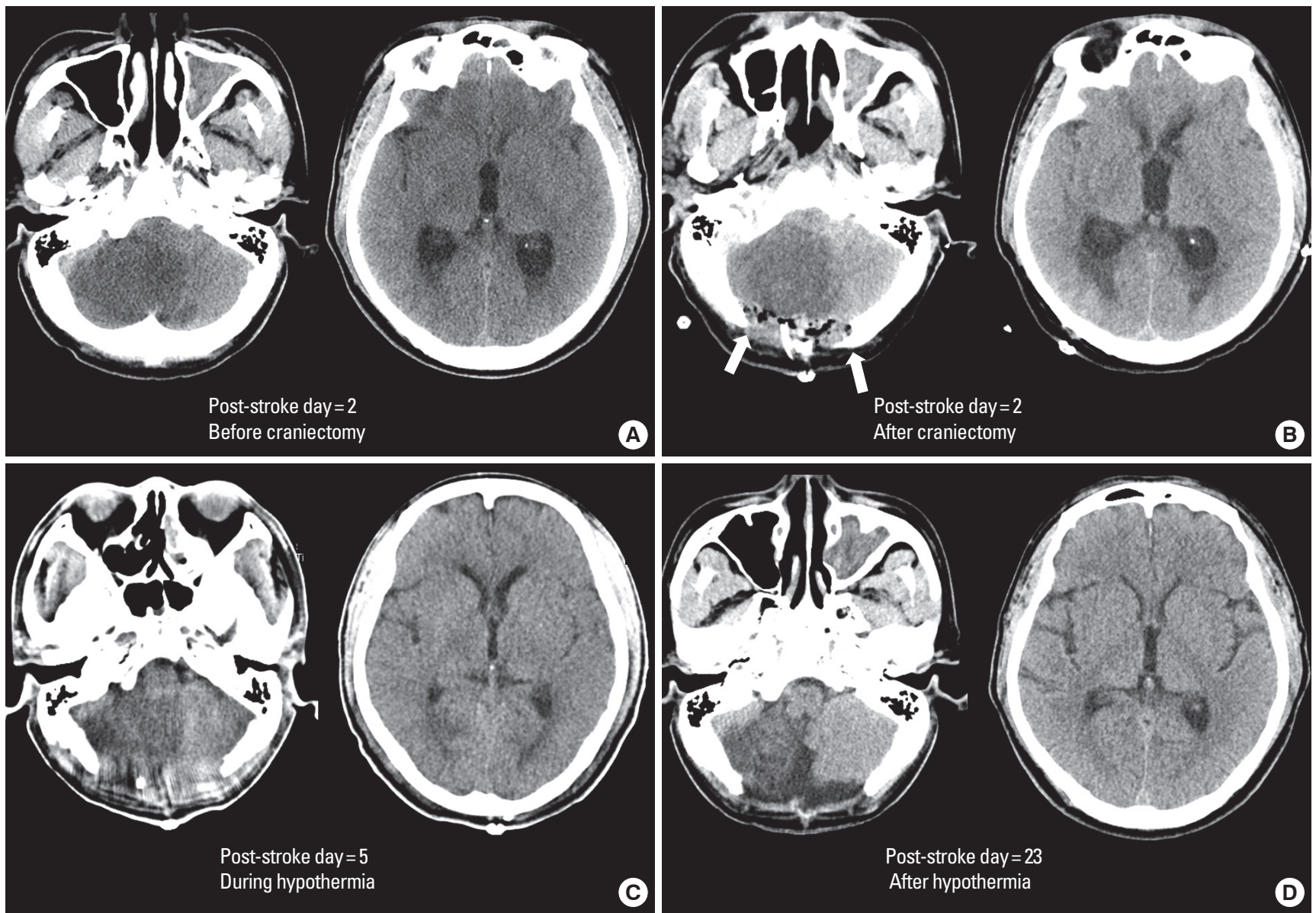

Figure 3. Suboccipital craniectomy, cerebrospinal fluid drainage, and therapeutic hypothermia for cerebellar infarction. Computed tomography images from a 50-years-old male with a history of hypertension and 30 pack-years of smoking who presented with sudden onset of vertigo. Images were obtained pre- (A) and post(B) craniectomy on post-stroke day 2, during hypothermia on post-stroke day 5 (C), and after hypothermia on post-stroke day 23 (D). Computed tomography obtained prior to craniectomy showed a massive infarct in the territory of the posterior inferior cerebellar artery and hydrocephalus (A). At this time, the patient's mental status had deteriorated to stupor. Suboccipital craniectomy was performed and the patient was comatose after the surgery. Cerebrospinal fluid was drained through an extraventricular drain but there was no prompt improvement in clinical condition. Therapeutic hypothermia with a target temperature of $33^{\circ} \mathrm{C}$ was performed for 3 days, and the patient became alert without significant deficits other than bilateral limb ataxia. At post-stroke day 23, the patient was discharged without neurological deficits except subtle truncal ataxia.

alus following cerebellar infarction, placement of an EVD (ventriculostomy) should be accompanied by suboccipital craniectomy. ${ }^{5}$

\section{Therapeutic hypothermia}

Clinical studies on therapeutic hypothermia have investigated the effects on two different outcomes: neuroprotection and ICP control. Therapeutic hypothermia is potentially neuroprotective through multiple mechanisms. Hypothermia reduces cerebral metabolism and consumption of oxygen and glucose by the brain, thereby preventing the failure of sodium transport and calcium influx, and decreasing the risk of cell death. ${ }^{47}$ Additional beneficial effects of hypothermia include the inhibition of excitatory neurotransmitters, free radicals, inflammation, and apoptosis. Reduced ICP is a robust manifestation of hypother- mia and is driven by reductions in cerebral blood volume, vasogenic edema and inflammation, and mitigation of blood-brain barrier leakage. ${ }^{47}$

In stroke patients, therapeutic effects of hypothermia are equivocal despite robust benefits in animal models and preclinical trials. Small pilot studies suggest possible benefits of therapeutic hypothermia in stroke (Table 3 ) and observational studies suggest that therapeutic hypothermia is a potent anti-edema strategy. Induced hypothermia with a target temperature of $32-33^{\circ} \mathrm{C}$ helped control ICP elevation due to cerebral edema in patients with malignant MCA infarction, ${ }^{48,49}$ and induced hypothermia with a target temperature of $34.5^{\circ} \mathrm{C}$ reduced cerebral edema and hemorrhagic transformation after successful recanalization for acute ischemic stroke. ${ }^{50}$ An anti-edema effect of hypothermia at $35^{\circ} \mathrm{C}$ for $8-10$ days has also been demonstrated in patients with intracerebral hemorrhage. ${ }^{51,52}$ ICP reduction does not nec- 
Table 3. Studies of therapeutic hypothermia in patients with ischemic stroke

\begin{tabular}{|c|c|c|c|c|c|c|c|c|}
\hline Author & Stroke type & Case (n) & $\begin{array}{l}\text { Time from } \\
\text { stroke onset }\end{array}$ & $\begin{array}{l}\text { Cooling } \\
\text { method }\end{array}$ & $\begin{array}{c}\text { Target } \\
\text { temperature }\end{array}$ & $\begin{array}{l}\text { Cooling } \\
\text { duration }\end{array}$ & $\begin{array}{l}\text { Clinical } \\
\text { outcomes }\end{array}$ & Comments \\
\hline Schwab et al. ${ }^{48}$ & mMCA & 25 & $<24 \mathrm{~h}$ & $S$ & $33^{\circ} \mathrm{C}$ & $48-72 \mathrm{~h}$ & Mortality 44\% & $\begin{array}{l}\text { Lower ICP and mortality compared with } \\
\text { natural history }\end{array}$ \\
\hline Kammersgaard et al. ${ }^{87}$ & mMCA & 17 & $<12 \mathrm{~h}$ & $S$ & $35.5^{\circ} \mathrm{C}$ & $6 \mathrm{~h}$ & No difference $^{\dagger}$ & Included patients with ICH \\
\hline Krieger et al. ${ }^{88}$ & mMCA & 10 & $<8 \mathrm{~h}$ & S & $32^{\circ} \mathrm{C}$ & $12-72 \mathrm{~h}$ & No difference ${ }^{\dagger}$ & Thrombolysis permitted \\
\hline Schwab et al. ${ }^{49}$ & mMCA & 50 & $\sim 23 \mathrm{~h}$ & S & $32-33^{\circ} \mathrm{C}$ & $24-72 h$ & Mortality 38\% & $\begin{array}{l}\text { Reduced ICP during hypothermia; } \\
\text { increased ICP and mortality since } \\
\text { rapid rewarming }\end{array}$ \\
\hline Georgiadis et al. ${ }^{89}$ & mMCA & 6 & $<58 \mathrm{~h}$ & $E$ & $33^{\circ} \mathrm{C}$ & $48-78 \mathrm{~h}$ & Mortality $17 \%$ & First report on endovascular cooling \\
\hline Georgiadis et al..$^{90}$ & mMCA & 19 & ns & $S, E$ & $33^{\circ} \mathrm{C}$ & $48-72 \mathrm{~h}$ & Improved $^{\ddagger}$ & $\begin{array}{l}\text { Compared craniectomy/hypothermia to } \\
\text { craniectomy }\end{array}$ \\
\hline De Geogia et al. ${ }^{91}$ & Ant. infarct & 18 & $<12 \mathrm{~h}$ & E & $33^{\circ} \mathrm{C}$ & $24 \mathrm{~h}$ & No difference ${ }^{\dagger}$ & Awake'; tPA; smaller lesion growth \\
\hline Wang et al..$^{92}$ & Severe stroke & 8 & ns & Head & $33-35^{\circ} \mathrm{C}$ & ns & ns & Included patients with TBI \\
\hline Milhaud et al. ${ }^{93}$ & mMCA & 12 & $<24 \mathrm{~h}$ & S & $32-33^{\circ} \mathrm{C}$ & $5-22 d$ & Mortality $42 \%$ & Craniectomy permitted \\
\hline Lyden et al. ${ }^{94}$ & Infarct & 18 & $<12 \mathrm{~h}$ & $E$ & $33^{\circ} \mathrm{C}$ & $12-24 \mathrm{~h}$ & Mortality $17 \%$ & Awake $^{\S}$ \\
\hline Els et al. ${ }^{95}$ & $\mathrm{mMCA}$ & 12 & ns & $S, E$ & $35^{\circ} \mathrm{C}$ & $48 \mathrm{~h}$ & Improved $^{\ddagger}$ & $\begin{array}{l}\text { Compared craniectomy/hypothermia to } \\
\text { craniectomy }\end{array}$ \\
\hline Guluma et al..$^{96}$ & Infarct & 10 & $<6 \mathrm{~h}$ & $E$ & $33^{\circ} \mathrm{C}$ & $24 \mathrm{~h}$ & ns & Awake»; tPA \\
\hline Martin-Schild et al. ${ }^{97}$ & Cortical infarct & 20 & $<5 h$ & $S, E$ & $33-34.5^{\circ} \mathrm{C}$ & $9-28 \mathrm{~h}$ & Improved ${ }^{\ddagger}$ & tPA; caffeinol plus hypothermia \\
\hline Hemmen et al..$^{98}$ & Infarct & 28 & $<6 \mathrm{~h}$ & $\mathrm{E}$ & $33^{\circ} \mathrm{C}$ & $24 \mathrm{~h}$ & No difference $^{\dagger}$ & Awake $^{\S}$ \\
\hline Bi et al. ${ }^{99}$ & Infarct & 31 & $<6 \mathrm{~h}$ & Head & ns & $24 \mathrm{~h}$ & No difference $^{\dagger}$ & $\begin{array}{l}\text { Awakes; cooled the lesion side of the } \\
\text { head }\end{array}$ \\
\hline Abou-Chebl et al. ${ }^{100}$ & Infarct & 15 & ns & Transnasal & $-1.1 \pm 0.6^{\circ} \mathrm{C}$ & ns & ns & $\begin{array}{l}\text { Awakes; included patients with ICH } \\
\text { and TBI }\end{array}$ \\
\hline Mourand et al. ${ }^{101}$ & mMCA & 19 & $<24 \mathrm{~h}$ & S & $32-33^{\circ} \mathrm{C}$ & $22.6 \pm 4.9$ days & Mortality 46\% & Craniectomy permitted \\
\hline Ovesen et al. ${ }^{102}$ & Infarct & 17 & $\sim 8.8 \mathrm{~h}$ & $S, E$ & $33^{\circ} \mathrm{C}$ & $24 \mathrm{~h}$ & No difference ${ }^{\dagger}$ & Thrombolysis permitted \\
\hline Hong et al. ${ }^{50}$ & Ant. infarct & 39 & ns & $S, E$ & $34.5^{\circ} \mathrm{C}$ & $48 \mathrm{~h}$ & Improved $^{\ddagger}$ & $\begin{array}{l}\text { Recanalyzed infarct with/without } \\
\text { thrombolysis }\end{array}$ \\
\hline Piironen et al. ${ }^{103}$ & Infarct & 18 & $<6.5 \mathrm{~h}$ & S & $34.5^{\circ} \mathrm{C}$ & $1-17 \mathrm{~h}$ & Improved $^{\ddagger}$ & Acute infarct after thrombolysis \\
\hline
\end{tabular}

Values are mean \pm standard deviation or range, as appropriate. mMCA, malignant MCA infarct; ant., anterior circulation; ns, not specified; ICH, intracerebral hemorrhage; TBI, traumatic brain injury; S, surface cooling; E, endovascular cooling; tPA, recombinant tissue plasminogen activator. ${ }^{\dagger}$ No difference, no difference in outcome between the hypothermia group and control group; ${ }^{\ddagger} I m p r o v e d$, more positive outcome in the hypothermia group than control group; ${ }^{\S} A$ wake, kept patients awake during hypothermia.

essarily equal improved clinical outcome. Nevertheless, therapeutic hypothermia is effective for ICP management, at least in selected patients (Figure 3). Currently, two major clinical trials of therapeutic hypothermia in patients with stroke are underway: The Intravenous Cooling in the Treatment of Stroke 2/3 (ICTuS 2/3) is a phase II-III trial of therapeutic hypothermia at $33^{\circ} \mathrm{C}$ for 24 hours in 1,600 stroke patients, and EuroHYP-1 is a phase III trial of therapeutic hypothermia at $34-35^{\circ} \mathrm{C}$ for 24 hours in 1,500 stroke patients. ${ }^{53}$ Despite the current lack of evidence from clinical trials on the neuroprotective effect of therapeutic hypothermia in stroke patients, the effect of therapeutic hypothermia on ICP reduction is unequivocal in patients with brain edema irrespective of the cause. ${ }^{54}$

In practice, therapeutic hypothermia can be separated into three phases: induction, maintenance, and rewarming. Induction is typically performed as rapidly as possible to a target temperature of $32-35^{\circ} \mathrm{C}$. For this purpose, ice packs and $4^{\circ} \mathrm{C}$ cold saline can be combined with a commercialized cooling device. During the maintenance period, only minor fluctuations in pa- tients' body temperature are allowed. The rewarming period is very important because rebound edema and ICP elevation may occur during this period. ${ }^{48}$ To avoid such detrimental effects, rewarming rates should be slow and are usually targeted at 0.1$0.25^{\circ} \mathrm{C} / \mathrm{h}$. Rebound hyperthermia after rewarming should also be avoided. Further clinical studies are required to determine the optimal therapeutic time window, target temperature, duration of cooling, and rewarming rate of therapeutic hypothermia for patients with stroke.

The prevention and management of various complications of therapeutic hypothermia is challenging. The most frequently encountered and cumbersome complication is shivering, especially when surface cooling is used rather than endovascular cooling. ${ }^{55}$ Shivering not only counteracts the cooling process but also has a harmful impact on systemic oxygen consumption, brain tissue oxygenation, and ICP. ${ }^{56,57}$ Our anti-shivering protocol developed according to a literature review and our clinical experience is shown in Table $4 .^{58}$ The masking of infection-induced fever is also a problem associated with therapeutic hypo- 
Table 4. Protocol for the management of shivering during therapeutic hypothermia

\begin{tabular}{|c|c|}
\hline Routine & $\begin{array}{l}\text { Skin counter warming } \\
\text { Acetaminophen ( } 500-1,000 \mathrm{mg} \text { every } 4 \mathrm{~h} \text { ) } \\
\text { Buspirone ( } 30 \mathrm{mg} \text { every } 8 \mathrm{~h} \text { ) } \\
\text { Magnesium sulphate (loading, } 4 \mathrm{~g} \text { iv over } 15 \mathrm{~min} \text {; maintenance, } \\
0.5-1.0 \mathrm{~g} / \mathrm{h} \text {; goal, } 3-4 \mathrm{mg} / \mathrm{dL} \text { ) }\end{array}$ \\
\hline Stepwise & $\begin{array}{l}\text { Dexmedetomidine (initial, } 0.5 \mu \mathrm{g} / \mathrm{kg} / \mathrm{h} \text {; maintenance, } 0.2-1.5 \mu \mathrm{g} / \mathrm{kg} / \mathrm{h} \text { ) } \\
\text { Fentanyl (loading, } 50-100 \mu \mathrm{g} \text { iv; maintenance, } 1-10 \mu \mathrm{g} / \mathrm{kg} / \mathrm{h} \text { ) } \\
\text { Propofol (loading, 0.5-1.0 mg/kg; maintenance, 0.3-5.0 mg/kg/h) } \\
\text { Cisatracurium (initial, } 3.0 \mu \mathrm{g} / \mathrm{kg} / \mathrm{min} \text {; maintenance, } 0.5-10.0 \mu \mathrm{g} / \mathrm{kg} / \mathrm{min} \text { ) }\end{array}$ \\
\hline Rescue $^{*}$ & $\begin{array}{l}\text { Meperidine }(50-100 \mathrm{mg}) \text { iv bolus } \\
\text { Cisatracurium }(0.1-0.2 \mathrm{mg} / \mathrm{kg}) \text { iv bolus }\end{array}$ \\
\hline
\end{tabular}

iv, intravenous. *Especially during the rapid induction period.

thermia. We have experienced some patients whose circulating water temperature in the cooling device could be used as a surrogate marker for increased heat production by the patient. Regular follow-ups of chest radiographs and laboratory tests including complete blood cell counts, C-reactive protein, procalcitonin, urinalysis, and surveillance cultures may also help early detection of infection. Other major complications of therapeutic hypothermia include pneumonia, pulmonary edema, hypotension, decreased cardiac output, bradycardia, conduction blocks, ileus, hepatic dysfunction, pancreatitis, hyperglycemia, cold diuresis, hypokalemia, hypomagnesemia, hypophosphatemia, hypocalcemia, alkalosis, hypocarbia, impaired immune function, bleeding diathesis, and alterations in pharmacokinetics and pharmacodynamics. Physicians utilizing therapeutic hypothermia should be familiar with the prevention and management of such complications.

\section{Ventilatory support}

Most stroke patients with mild respiratory difficulties can be managed with supportive care such as insertion of an oral airway, supplemental oxygen, and antibiotics for aspiration pneumonia. However, patients who are stuporous or comatose following massive stroke can develop reduced oropharyngeal muscle tone that leads to posterior displacement of the tongue and airway obstruction. A decrease in or absence of gag and cough reflexes and impaired immune function further increase the risk of aspiration. Therefore, these patients are vulnerable to hypoxia, aspiration pneumonia, and respiratory distress and arrest unless preemptive endotracheal intubation and mechanical ventilation are applied. For safe intubation, RSI is necessary. RSI involves prompt induction of sedation and subsequent endotracheal intubation. Etomidate is the preferred induction agent for stroke patients because of its short-acting characteristics and hemodynamic stability. However, it is not recommended for patients with seizures or adrenal insufficiency. Other induction agents include propofol and midazolam. Succinylcholine is the most commonly administered neuromuscular blocking agent for RSI as a result of its rapid onset and short duration of action. However, a brief increase in ICP has been reported following administration of succinylcholine..$^{59}$ Other possible side effects of succinylcholine are malignant hyperthermia, hyperkalemia, and aggravation of neuropathy or myopathy. ${ }^{59}$ For this reason, some experts recommend non-depolarizing neuromuscular blocking agents such as cisatracurium and rocuronium for RSI. ${ }^{59}$ Fentanyl can reduce the increase in blood pressure and ICP that occurs during intubation and is usually administered to stroke patients undergoing RSI, whereas lidocaine minimizes coughing and the increase in ICP. ${ }^{60}$

Intubated patients usually require mechanical ventilation. Inappropriate management of mechanically ventilated patients with space-occupying stroke can lead to lung damage as well as brain damage. Injuries to the lungs are attributable to a high endinspiratory and low end-expiratory lung volume which results in repeated collapse and re-expansion. A high shear force is exerted on alveolar walls and small airways during inflation, especially at the interfaces between collapsed and aerated alveoli. ${ }^{61}$ Application of positive end-expiratory pressure (PEEP) can avoid repeated alveoli collapse. However, the effect of PEEP on cerebral physiology is controversial. PEEP can elevate ICP through increased thoracic pressure and decreased MAP, venous return, and cardiac output. One study increased PEEP up to 12 $\mathrm{cmH}_{2} \mathrm{O}$ in patients with acute stroke, but ICP remained unchanged or slightly reduced. ${ }^{62}$ There was marked decrease in CPP caused by the decrease in MAP. In general, increasing PEEP up to $20 \mathrm{cmH}_{2} \mathrm{O}$ does not have deleterious effects on ICP as long as the baseline ICP is not high $(<20 \mathrm{mmHg}){ }^{63}$ The benefits of PEEP may outweigh the risks of hypoxemia in patients with stroke. A strategy of maintaining a low tidal volume and limiting plateau pressure is also necessary to restrict end-inspiratory overexpansion of alveoli. Tidal volume should be limited to $6-8 \mathrm{~mL} /$ $\mathrm{kg}$ of predicted body weight, especially for patients with acute respiratory distress syndrome (ARDS) ${ }^{64}$ However, low tidal volume reduces carbon dioxide elimination via the lungs and can cause hypercapnia and respiratory acidosis. Subsequent hyperventilation stimulates the brainstem respiratory center and may cause ventilator dyssynchrony and require heavy sedation or neuromuscular blockade. Hypercapnia causes intracranial hypertension by dilating cerebral vessels and increasing CBF. However, the risk of increased ICP as a consequence of permissive hypercapnia has not been studied in stroke patients. ${ }^{65}$ Pumpless extracorporeal lung assist combined with lung-protective ventilation may be used as an adjunctive therapy in patients with 
both ICP crisis and hypercapnia caused by low tidal volume. ${ }^{66}$ This can be used to address hypercapnia-associated increases in ICP, and the minute volume of the ventilator can be reduced to avoid hyperinflation of alveoli.

\section{Sedation and analgesia}

Sedation and analgesia are often required in patients with malignant brain edema following stroke. They can be used to manage ICP and CPP as well as attenuate the stress response, increase endotracheal tube tolerance, reduce metabolic energy demands, prevent delirium and decrease patient-ventilator synchrony. ${ }^{67}$ In the neurological ICU, sedation and analgesia are typically induced by continuous infusion of fentanyl, remifentanil, propofol, midazolam, or dexmedetomidine. Clinical studies that compare the efficacy of these agents are lacking in patients with stroke. In general, the different intravenous opioids are equally effective when titrated to similar pain intensity endpoints. ${ }^{68}$ Fentanyl, a $\mu$-receptor agonist, is popular in the ICU as a result of its strong analgesic effect, lack of neurotoxicity, rapid onset of action, and short elimination half-life. Remifentanil, an opioid agent that is chemically related to fentanyl, may be preferred to fentanyl as a result of its shorter elimination half-life and its lack of accumulation in patients with hepatic or renal failure. A short context-sensitive half-time - the time required for blood or plasma concentrations of a drug to decrease by $50 \%$ after discontinuation of drug administration-is an attractive characteristic of remifentanil when frequent wake-up tests for neurological evaluation and ventilator weaning are planned. Propofol has sedative, hypnotic, anxiolytic, amnestic, antiemetic, and anticonvulsant properties, but no analgesic effects. ${ }^{69}$ The rapid onset and short duration of action of propofol are advantageous if frequent wake-up tests are required and this agent may have stronger sup- pressive effects on cerebral metabolism than midazolam. ${ }^{70}$ However, propofol may lead to dose-dependent respiratory depression and hypotension. When administered at a high dose for a prolonged period ( $>4 \mathrm{mg} / \mathrm{kg} / \mathrm{h}$ for $>48 \mathrm{~h}$ ), propofol may cause propofol infusion syndrome, which is characterized by various early signs including lactic acidosis, triglyceridemia, bradycardia, and Brugada-like electrocardiogram changes, and later signs including cardiac failure, tachyarrhythmia or heart block, ventricular tachycardia, rhabdomyolysis, hyperkalemia, renal failure, and fatty degeneration of the liver. ${ }^{71}$ Among the benzodiazepines, midazolam is often used for continuous infusion in the ICU as it has a faster onset, more rapid clearance, and shorter duration of action than lorazepam. However, with prolonged use, it exhibits greater variability and longer time to awakening than lorazepam. It also contains propylene glycol, which can cause metabolic acidosis and acute kidney injury. ${ }^{72}$ Dexmedetomidine is a selective alpha 2-receptor agonist with sedative, analgesic, and sympatholytic properties, but no anticonvulsive properties. ${ }^{73}$ Patients sedated with this agent are more easily aroused and more interactive than patients sedated with other drugs. ${ }^{74}$ Another characteristic of dexmedetomidine that is useful in the neurological ICU is the minimal respiratory depression and anti-shivering effects. In mechanically ventilated adult ICU patients at risk of developing delirium, dexmedetomidine infusion for sedation was associated with a lower prevalence of delirium than benzodiazepine infusion. ${ }^{75}$ However, dexmedetomidine frequently causes bradycardia, hypotension, and hypertension, especially after the loading dose. For this reason, we prefer starting with a maintenance dose of $0.5 \mu \mathrm{g} / \mathrm{kg} / \mathrm{h}$ without a loading dose. Dexmedetomidine is becoming increasingly popular in the neurological ICU. Physicians who manage stroke patients in the ICU should be familiar with the characteristics of each sedative and analgesic agent (Table 5). ${ }^{6}$

Table 5. Continuous infusion for sedation and analgesia in the intensive care unit

\begin{tabular}{|c|c|c|c|c|}
\hline & $\begin{array}{c}\text { Onset of } \\
\text { drug effect }\end{array}$ & $\begin{array}{c}\text { Elimination half-life } \\
\text { (Context-sensitive half-time) }\end{array}$ & Dose & Comments \\
\hline \multicolumn{5}{|l|}{ Analgesic } \\
\hline Fentanyl & $1-2 \mathrm{~min}$ & $\begin{array}{l}\text { 2-4 } \mathrm{h} \text { (200 min after } 6 \text { h infusion; } \\
300 \text { min after } 12 \mathrm{~h} \text { infusion) }\end{array}$ & $\begin{array}{l}\text { Loading, } 25-50 \mu \mathrm{g} \\
\text { Maintenance, } 0.7-10 \mu \mathrm{g} / \mathrm{kg} / \mathrm{h}\end{array}$ & Accumulation with hepatic impairment \\
\hline Remifentanil & $1-3 \mathrm{~min}$ & $3-10 \min (3-4 \mathrm{~min})$ & $\begin{array}{l}\text { Loading, } 1-1.5 \mu \mathrm{g} / \mathrm{kg} \\
\text { Maintenance, } 0.025-0.2 \mu \mathrm{g} / \mathrm{kg} / \mathrm{min}\end{array}$ & $\begin{array}{l}\text { No accumulation in hepatic/renal failure; use IBW if body weight } \\
>130 \% \text { IBW }\end{array}$ \\
\hline \multicolumn{5}{|c|}{ (- } \\
\hline Propofol & $1-2 \mathrm{~min}$ & $\begin{array}{l}\text { (3-12 } \mathrm{h} \text { after short-term use; } \\
50 \pm 18.6 \text { h after long-term use) }\end{array}$ & $\begin{array}{l}\text { Loading, } 0.5-1 \mathrm{mg} / \mathrm{kg} \text { over } 5 \mathrm{~min} \\
\text { Maintenance, } 0.3-4 \mathrm{mg} / \mathrm{kg} / \mathrm{h}\end{array}$ & $\begin{array}{l}\text { Pain at injection site, hypotension, propofol infusion syndrome, } \\
\text { hypertriglyceridemia, pancreatitis }\end{array}$ \\
\hline Midazolam & $2-5 \min$ & $3-11 \mathrm{~h}$ & $\begin{array}{l}\text { Loading, } 0.01-0.08 \mathrm{mg} / \mathrm{kg} \\
\text { Maintenance, } 0.02-0.2 \mathrm{mg} / \mathrm{kg} / \mathrm{h}\end{array}$ & Active metabolites; less hypotension than with propofol \\
\hline \multicolumn{5}{|l|}{ Analgosedative } \\
\hline Dexmedetomidine & $5-10 \mathrm{~min}$ & $\begin{array}{l}\text { 1.8-3.1 } \mathrm{h} \text { ( } 250 \mathrm{~min} \text { after } 8 \mathrm{~h} \\
\text { infusion) }\end{array}$ & $\begin{array}{l}\text { Loading, } 1 \mu \mathrm{gg} / \mathrm{kg} \text { over } 10 \mathrm{~min} \\
\text { Maintenance, } 0.2-1.5 \mu \mathrm{gg} / \mathrm{kg} / \mathrm{h}\end{array}$ & $\begin{array}{l}\text { No or minimal respiratory suppression, shivering control, } \\
\text { bradycardia, hypotension, dry mouth, loss of airway reflex }\end{array}$ \\
\hline
\end{tabular}

Values are mean \pm standard deviation or range, as appropriate. IBW, ideal body weight. 
Neurological examination remains the most valuable tool for the assessment of stroke patients. The requirement for a reliable neurological examination conflicts with the requirement for sedation and analgesia in patients with massive stroke and mechanical ventilation. The sedation and analgesia regimen should utilize the minimum amount of drugs possible to adequately maintain a safe environment for ventilation and for cerebral and systemic hemodynamics during periods requiring tracking of neurological status. ${ }^{76}$ A regular wake-up test is an important evaluation measure in the neurological ICU. To perform this test, infusion of sedatives and analgesic agents should be interrupted temporarily. Precise assessment and neurological tracking can be helpful for planning neuroimaging studies and medical or surgical interventions. However, a wake-up test may cause an ICP surge, agitation, systemic desaturation, a decrease in brain tissue oxygen tension, and cerebral metabolic distress. ${ }^{76}$ Thus, neurological wake-up tests are controversial as a result of the risk of a stress response and the uncertainty of its clinical value. Early studies showed that a daily wake-up test was associated with a shorter ICU stay and a more positive outcome in general ICU patients. ${ }^{77,78}$ However, in more recent studies, evidence to support the overall benefit of a wake-up test has been equivo$\mathrm{cal}^{79-82}$ It is considered safe for medical and surgical ICU patients but has not been validated for patients in neurological ICU. ${ }^{77,78,83}$ In a prospective observational study, patients with acute brain injury developed a critical increase in ICP and impending brain tissue hypoxia as well as a sympathetic stress response with increased heart rate, respiratory rate, and blood pressure during interruption of sedatives for neurological examination. ${ }^{76}$ In a subgroup of patients with lower cerebral compliance, a wake-up test induced marked changes in ICP and CPP that could potentially have a negative impact on the injured brain. Thus, these patients need to be excluded from repeated wake-up tests, and information should instead be gathered from multimodal neuromonitoring in combination with neuroimaging studies. ${ }^{84}$ During a wake-up test, ICP and CPP often increase slightly and tolerably from baseline levels. In the majority of patients, these changes are mild, transient and acceptable, and do not preclude further repetitions of the test. Nevertheless, abrupt cessation of sedatives and analgesic agents is stressful to patients. A recent observational study showed that wake-up tests induced a biochemical stress response in patients with traumatic brain injury. ${ }^{85}$ Stress hormones including adrenocorticotrophic hormone, epinephrine, norepinephrine, and cortisol as well as physiological variables like blood pressure, heart rate, ICP, and CPP increased significantly immediately after wake-up tests. ${ }^{85}$ The short- and long-term consequences of the test are unclear at present. Therefore, it is important to consider the advantages and disadvantag- es of interrupting sedation and analgesia and stimulating patients for a wake-up test during an ICP crisis. Given the limited knowledge on the benefits of interrupting sedation and analgesia for wake-up tests, multimodal neuromonitoring and neuroimaging in neurocritical care may be helpful in unconscious patients with stroke.

Once the clinical condition of the patient improves, sedatives and analgesics should be tapered and suspended. Definitive interruption is possible when the clinical and cerebral state of the patient do not justify sedation. However, acute withdrawal symptoms are not uncommon following abrupt cessation of sedatives and analgesics. This phenomenon is similar to paroxysmal sympathetic hyperactivity, i.e., episodic manifestations of fevers, diaphoresis, hypertension, tachycardia, tachypnea, and dystonic posturing. ${ }^{86}$ In this situation, sedatives and analgesics should be reinstituted and tapered slowly again after such symptoms disappear.

\section{Conclusions}

Brain swelling following stroke can cause secondary cerebral ischemia, herniation syndrome, and brain death. Aggressive medical and surgical treatment for brain swelling is necessary to prevent detrimental outcomes. General medical care is paramount because a complex interaction exists between the brain and other organs. The importance of total body care cannot be overemphasized: attention should be paid not only to the brain, but also to the other regions of the body. The advantages and limitations of each treatment should always be considered because the appropriate treatment for one area of the body may contradict the appropriate treatment for another.

\section{References}

1. Simard JM, Kent TA, Chen M, Tarasov KV, Gerzanich V. Brain oedema in focal ischaemia: molecular pathophysiology and theoretical implications. Lancet Neurol 2007;6:258-268.

2. Mokri B. The Monro-Kellie hypothesis: applications in CSF volume depletion. Neurology 2001;56:1746-1748.

3. Ropper AH. Management of intracranial hypertension and mass effect. In: Ropper AH. Neurological and Neurosurgical Intensive Care. 4th ed. Charlottesville, VA: Lippincott Williams \& Wilkins, 2004;26-51.

4. Brazis PW, Masdeu JC, Biller J. The localization of lesions causing coma. In: Brazis PW, Masdeu JC, Biller J. Localization in Clinical Neurology. 5th ed. Philadelphia, PA: Lippincott Williams \& Wilkins, 2007;557-582.

5. Wijdicks EF, Sheth KN, Carter BS, Greer DM, Kasner SE, Kim- 
berly WT, et al. Recommendations for the management of cerebral and cerebellar infarction with swelling: a statement for healthcare professionals from the American Heart Association /American Stroke Association. Stroke 2014;45:1222-1238.

6. Stephensen H, Tisell M, Wikkelso C. Intracranial pressure during wakefulness and sleep in 55 adult patients with chronic hydrocephalus. Neurosurgery 2006;59:326-332; discussion 326-332.

7. Marmarou A, Anderson RL, Ward JD, Choi SC, Young HF. Impact of ICP instability and hypotension on outcome in patients with severe head trauma. J Neurosurg 1991;75:S59-S66.

8. Steiner LA, Andrews PJ. Monitoring the injured brain: ICP and CBF. Br J Anaesth 2006;97:26-38.

9. Ko SB. Multimodality monitoring in the neurointensive care unit: a special perspective for patients with stroke. J Stroke 2013; 15:99-108

10. Schwab S, Aschoff A, Spranger M, Albert F, Hacke W. The value of intracranial pressure monitoring in acute hemispheric stroke. Neurology 1996;47:393-398.

11. Poca MA, Benejam B, Sahuquillo J, Riveiro M, Frascheri L, Merino MA, et al. Monitoring intracranial pressure in patients with malignant middle cerebral artery infarction: is it useful? J Neurosurg 2010;112:648-657.

12. Chesnut RM, Temkin N, Carney N, Dikmen S, Rondina C, Videtta W, et al. A trial of intracranial-pressure monitoring in traumatic brain injury. N Engl J Med 2012;367:2471-2481.

13. Adler DE, Milhorat TH. The tentorial notch: anatomical variation, morphometric analysis, and classification in 100 human autopsy cases. J Neurosurg 2002;96:1103-1112.

14. Rosenwasser RH, Kleiner LI, Krzeminski JP, Buchheit WA. Intracranial pressure monitoring in the posterior fossa: a preliminary report. J Neurosurg 1989;71:503-505.

15. Wartenberg KE, Schmidt JM, Mayer SA. Multimodality monitoring in neurocritical care. Crit Care Clin 2007;23:507-538.

16. Czosnyka M. Increased intracranial pressure: what to do about it and when? Crit Care Med 2013;41:688.

17. Schreckinger M, Marion DW. Contemporary management of traumatic intracranial hypertension: is there a role for therapeutic hypothermia? Neurocrit Care 2009;11:427-436.

18. Kiening KL, Hartl R, Unterberg AW, Schneider GH, Bardt T, Lanksch WR. Brain tissue PO2-monitoring in comatose patients: implications for therapy. Neurol Res 1997;19:233-240.

19. Lee K and Mayer SA. Management of increased intracranial pressure. In: Kiwon L. The NeuroICU Book. 1st ed. New York, NY: McGraw-Hill, 2012;213-225.

20. Muizelaar JP, Marmarou A, Ward JD, Kontos HA, Choi SC, Becker DP, et al. Adverse effects of prolonged hyperventilation in patients with severe head injury: a randomized clinical trial. J Neurosurg 1991;75:731-739.

21. Rosner MJ, Becker DP. Origin and evolution of plateau waves. Experimental observations and a theoretical model. J Neurosurg 1984;60:312-324.

22. Grande PO. The "Lund Concept" for the treatment of severe head trauma--physiological principles and clinical application. Intensive Care Med 2006;32:1475-1484.

23. Steiner LA, Czosnyka M, Piechnik SK, Smielewski P, Chatfield D, Menon DK, et al. Continuous monitoring of cerebrovascular pressure reactivity allows determination of optimal cerebral perfusion pressure in patients with traumatic brain injury. Crit Care Med 2002;30:733-738.

24. Garcia-Morales EJ, Cariappa R, Parvin CA, Scott MG, Diringer MN. Osmole gap in neurologic-neurosurgical intensive care unit: Its normal value, calculation, and relationship with mannitol serum concentrations. Crit Care Med 2004;32:986991.

25. Torre-Healy A, Marko NF, Weil RJ. Hyperosmolar therapy for intracranial hypertension. Neurocrit Care 2012;17:117-130.

26. Lazaridis C, Neyens R, Bodle J, DeSantis SM. High-osmolarity saline in neurocritical care: systematic review and meta-analysis. Crit Care Med 2013;41:1353-1360.

27. Georgiadis AL, Suarez JI. Hypertonic saline for cerebral edema. Curr Neurol Neurosci Rep 2003;3:524-530.

28. Eisenberg HM, Frankowski RF, Contant CF, Marshall LF, Walker MD. High-dose barbiturate control of elevated intracranial pressure in patients with severe head injury. J Neurosurg 1988; 69:15-23.

29. Roberts I, Sydenham E. Barbiturates for acute traumatic brain injury. Cochrane Database Syst Rev 2012;12:CD000033.

30. Hacke W, Schwab S, Horn M, Spranger M, De Georgia M, von Kummer R. 'Malignant' middle cerebral artery territory infarction: clinical course and prognostic signs. Arch Neurol 1996;53:309-315.

31. Vahedi K, Vicaut E, Mateo J, Kurtz A, Orabi M, Guichard JP, et al. Sequential-design, multicenter, randomized, controlled trial of early decompressive craniectomy in malignant middle cerebral artery infarction (DECIMAL Trial). Stroke 2007;38: 2506-2517.

32. Juttler E, Schwab S, Schmiedek P, Unterberg A, Hennerici M, Woitzik J, et al. Decompressive Surgery for the Treatment of Malignant Infarction of the Middle Cerebral Artery (DESTINY): a randomized, controlled trial. Stroke 2007;38:2518-2525.

33. Vahedi K, Hofmeijer J, Juettler E, Vicaut E, George B, Algra A, et al. Early decompressive surgery in malignant infarction of the middle cerebral artery: a pooled analysis of three randomised controlled trials. Lancet Neurol 2007;6:215-222.

34. Hofmeijer J, Kappelle LJ, Algra A, Amelink GJ, van Gijn J, van 
der Worp HB, et al. Surgical decompression for space-occupying cerebral infarction (the Hemicraniectomy After Middle Cerebral Artery infarction with Life-threatening Edema Trial [HAMLET]): a multicentre, open, randomised trial. Lancet Neurol 2009;8:326-333.

35. Juttler E, Unterberg A, Woitzik J, Bosel J, Amiri H, Sakowitz OW, et al. Hemicraniectomy in older patients with extensive middle-cerebral-artery stroke. N Engl J Med 2014;370:10911100 .

36. Kasner SE, Demchuk AM, Berrouschot J, Schmutzhard E, Harms L, Verro $P$, et al. Predictors of fatal brain edema in massive hemispheric ischemic stroke. Stroke 2001;32:2117-2123.

37. Qureshi AI, Suarez JI, Yahia AM, Mohammad Y, Uzun G, Suri MF, et al. Timing of neurologic deterioration in massive middle cerebral artery infarction: a multicenter review. Crit Care Med 2003;31:272-277.

38. Berrouschot J, Sterker M, Bettin S, Koster J, Schneider D. Mortality of space-occupying ('malignant') middle cerebral artery infarction under conservative intensive care. Intensive Care Med 1998;24:620-623.

39. Rahme R, Zuccarello M, Kleindorfer D, Adeoye OM, Ringer AJ. Decompressive hemicraniectomy for malignant middle cerebral artery territory infarction: is life worth living? $\mathrm{J} \mathrm{Neu}$ rosurg 2012;117:749-754.

40. Gupta R, Connolly ES, Mayer S, Elkind MS. Hemicraniectomy for massive middle cerebral artery territory infarction: a systematic review. Stroke 2004;35:539-543.

41. Tchopev Z, Hiller M, Zhuo J, Betz J, Gullapalli R, Sheth KN. Prediction of poor outcome in cerebellar infarction by diffusion MRI. Neurocrit Care 2013;19:276-282.

42. Jauss M, Krieger D, Hornig C, Schramm J, Busse O. Surgical and medical management of patients with massive cerebellar infarctions: results of the German-Austrian Cerebellar Infarction Study. J Neurol 1999;246:257-264.

43. Tsitsopoulos PP, Tobieson L, Enblad P, Marklund N. Surgical treatment of patients with unilateral cerebellar infarcts: clinical outcome and prognostic factors. Acta Neurochir (Wien) 2011;153:2075-2083.

44. Tsitsopoulos PP, Tobieson L, Enblad P, Marklund N. Clinical outcome following surgical treatment for bilateral cerebellar infarction. Acta Neurol Scand 2011;123:345-351.

45. Juttler E, Schweickert S, Ringleb PA, Huttner HB, Kohrmann $\mathrm{M}$, Aschoff A. Long-term outcome after surgical treatment for space-occupying cerebellar infarction: experience in 56 patients. Stroke 2009;40:3060-3066.

46. Pfefferkorn T, Eppinger U, Linn J, Birnbaum T, Herzog J, Straube A, et al. Long-term outcome after suboccipital decompressive craniectomy for malignant cerebellar infarction. Stroke 2009;
40:3045-3050.

47. Polderman KH. Mechanisms of action, physiological effects, and complications of hypothermia. Crit Care Med 2009;37: S186-202.

48. Schwab S, Schwarz S, Spranger M, Keller E, Bertram M, Hacke W. Moderate hypothermia in the treatment of patients with severe middle cerebral artery infarction. Stroke 1998;29:24612466.

49. Schwab S, Georgiadis D, Berrouschot J, Schellinger PD, Graffagnino C, Mayer SA. Feasibility and safety of moderate hypothermia after massive hemispheric infarction. Stroke 2001;32: 2033-2035.

50. Hong JM, Lee JS, Song HJ, Jeong HS, Choi HA, Lee K. Therapeutic hypothermia after recanalization in patients with acute ischemic stroke. Stroke 2014;45:134-140.

51. Kollmar R, Staykov D, Dorfler A, Schellinger PD, Schwab S, Bardutzky J. Hypothermia reduces perihemorrhagic edema after intracerebral hemorrhage. Stroke 2010;41:1684-1689.

52. Staykov D, Wagner I, Volbers B, Doerfler A, Schwab S, Kollmar R. Mild prolonged hypothermia for large intracerebral hemorrhage. Neurocrit Care 2013;18:178-183.

53. Kollmar R, Gebhardt B, Schwab S. EuroHYP-1 trial: EU-funded therapy study on the effectiveness of mild therapeutic hypothermia for acute ischemic stroke. Nervenarzt 2012;83:12521259.

54. Polderman KH. Induced hypothermia and fever control for prevention and treatment of neurological injuries. Lancet 2008; 371:1955-1969.

55. Hoedemaekers CW, Ezzahti M, Gerritsen A, van der Hoeven JG. Comparison of cooling methods to induce and maintain normo- and hypothermia in intensive care unit patients: a prospective intervention study. Crit Care 2007;11:R91.

56. Badjatia N, Strongilis E, Gordon E, Prescutti M, Fernandez L, Fernandez A, et al. Metabolic impact of shivering during therapeutic temperature modulation: the Bedside Shivering Assessment Scale. Stroke 2008;39:3242-3247.

57. Badjatia N, Strongilis E, Prescutti M, Fernandez L, Fernandez A, Buitrago M, et al. Metabolic benefits of surface counter warming during therapeutic temperature modulation. Crit Care Med 2009;37:1893-1897.

58. Choi HA, Badjatia N, Mayer SA. Hypothermia for acute brain injury--mechanisms and practical aspects. Nat Rev Neurol 2012; 8:214-222.

59. Booij LH. Is succinylcholine appropriate or obsolete in the intensive care unit? Crit Care 2001;5:245-246.

60. Hamill JF, Bedford RF, Weaver DC, Colohan AR. Lidocaine before endotracheal intubation: intravenous or laryngotracheal? Anesthesiology 1981;55:578-581. 
61. Mascia L, Mastromauro I, Viberti S. High tidal volume as a predictor of acute lung injury in neurotrauma patients. Minerva Anestesiol 2008;74:325-327.

62. Georgiadis D, Schwarz S, Baumgartner RW, Veltkamp R, Schwab S. Influence of positive end-expiratory pressure on intracranial pressure and cerebral perfusion pressure in patients with acute stroke. Stroke 2001;32:2088-2092.

63. Muench E, Bauhuf C, Roth H, Horn P, Phillips M, Marquetant $\mathrm{N}$, et al. Effects of positive end-expiratory pressure on regional cerebral blood flow, intracranial pressure, and brain tissue oxygenation. Crit Care Med 2005;33:2367-2372.

64. The Acute Respiratory Distress Syndrome Network. Ventilation with lower tidal volumes as compared with traditional tidal volumes for acute lung injury and the acute respiratory distress syndrome. N Engl J Med 2000;342:1301-1308.

65. Lowe GJ, Ferguson ND. Lung-protective ventilation in neurosurgical patients. Curr Opin Crit Care 2006;12:3-7.

66. Bein T, Kuhr LP, Metz C, Woertgen C, Philipp A, Taeger K. ARDS and severe brain injury. Therapeutic strategies in conflict. Anaesthesist 2002;51:552-556.

67. Beretta L, De Vitis A, Grandi E. Sedation in neurocritical patients: is it useful? Minerva Anestesiol 2011;77:828-834.

68. Barr J, Pandharipande PP. The pain, agitation, and delirium care bundle: synergistic benefits of implementing the 2013 Pain, Agitation, and Delirium Guidelines in an integrated and interdisciplinary fashion. Crit Care Med 2013;41:S99-115.

69. McKeage K, Perry CM. Propofol: a review of its use in intensive care sedation of adults. CNS Drugs 2003;17:235-272.

70. Helmy A, Vizcaychipi M, Gupta AK. Traumatic brain injury: intensive care management. Br J Anaesth 2007;99:32-42.

71. Wong JM. Propofol infusion syndrome. Am J Ther 2010;17: 487-491.

72. Yaucher NE, Fish JT, Smith HW, Wells JA. Propylene glycolassociated renal toxicity from lorazepam infusion. Pharmacotherapy 2003;23:1094-1099.

73. Bhana N, Goa KL, McClellan KJ. Dexmedetomidine. Drugs 2000;59:263-268; discussion 269-270.

74. Triltsch AE, Welte M, von Homeyer P, Grosse J, Genahr A, Moshirzadeh $\mathrm{M}$, et al. Bispectral index-guided sedation with dexmedetomidine in intensive care: a prospective, randomized, double blind, placebo-controlled phase II study. Crit Care Med 2002;30:1007-1014.

75. Riker RR, Shehabi Y, Bokesch PM, Ceraso D, Wisemandle W, Koura F, et al. Dexmedetomidine vs midazolam for sedation of critically ill patients: a randomized trial. JAMA 2009;301: 489-499.

76. Helbok R, Kurtz P, Schmidt MJ, Stuart MR, Fernandez L, Connolly SE, et al. Effects of the neurological wake-up test on clin- ical examination, intracranial pressure, brain metabolism and brain tissue oxygenation in severely brain-injured patients. Crit Care 2012;16:R226.

77. Kress JP, Pohlman AS, O’Connor MF, Hall JB. Daily interruption of sedative infusions in critically ill patients undergoing mechanical ventilation. N Engl J Med 2000;342:1471-1477.

78. Girard TD, Kress JP, Fuchs BD, Thomason JW, Schweickert WD, Pun BT, et al. Efficacy and safety of a paired sedation and ventilator weaning protocol for mechanically ventilated patients in intensive care (Awakening and Breathing Controlled trial): a randomised controlled trial. Lancet 2008;371:126-134.

79. Anifantaki S, Prinianakis G, Vitsaksaki E, Katsouli V, Mari S, Symianakis A, et al. Daily interruption of sedative infusions in an adult medical-surgical intensive care unit: randomized controlled trial. J Adv Nurs 2009;65:1054-1060.

80. Augustes R, Ho KM. Meta-analysis of randomised controlled trials on daily sedation interruption for critically ill adult patients. Anaesth Intensive Care 2011;39:401-409.

81. Bucknall TK, Manias E, Presneill JJ. A randomized trial of protocol-directed sedation management for mechanical ventilation in an Australian intensive care unit. Crit Care Med 2008; 36:1444-1450.

82. Mehta S, Burry L, Cook D, Fergusson D, Steinberg M, Granton J, et al. Daily sedation interruption in mechanically ventilated critically ill patients cared for with a sedation protocol: a randomized controlled trial. JAMA 2012;308:1985-1992.

83. Martin J, Franck M, Sigel S, Weiss M, Spies C. Changes in sedation management in German intensive care units between 2002 and 2006: a national follow-up survey. Crit Care 2007; 11:R124.

84. Prisco L, Citerio G. To wake-up, or not to wake-up: that is the Hamletic neurocritical care question! Crit Care 2012;16:190.

85. Skoglund K, Hillered L, Purins K, Tsitsopoulos PP, Flygt J, Engquist $\mathrm{H}$, et al. The Neurological Wake-up Test Does not Alter Cerebral Energy Metabolism and Oxygenation in Patients with Severe Traumatic Brain Injury. Neurocrit Care 2014;20:413426.

86. Choi HA, Jeon SB, Samuel S, Allison T, Lee K. Paroxysmal sympathetic hyperactivity after acute brain injury. Curr Neurol Neurosci Rep 2013;13:370.

87. Kammersgaard LP, Rasmussen BH, Jorgensen HS, Reith J, Weber U, Olsen TS. Feasibility and safety of inducing modest hypothermia in awake patients with acute stroke through surface cooling: A case-control study: the Copenhagen Stroke Study. Stroke 2000;31:2251-2256.

88. Krieger DW, De Georgia MA, Abou-Chebl A, Andrefsky JC, Sila CA, Katzan IL, et al. Cooling for acute ischemic brain damage (COOL AID): an open pilot study of induced hypo- 
thermia in acute ischemic stroke. Stroke 2001;32:1847-1854.

89. Georgiadis D, Schwarz S, Kollmar R, Schwab S. Endovascular cooling for moderate hypothermia in patients with acute stroke: first results of a novel approach. Stroke 2001;32:2550-2553.

90. Georgiadis D, Schwarz S, Aschoff A, Schwab S. Hemicraniectomy and moderate hypothermia in patients with severe ischemic stroke. Stroke 2002;33:1584-1588.

91. De Georgia MA, Krieger DW, Abou-Chebl A, Devlin TG, Jauss M, Davis SM, et al. Cooling for Acute Ischemic Brain Damage (COOL AID): a feasibility trial of endovascular cooling. Neurology 2004;63:312-317.

92. Wang H, Olivero W, Lanzino G, Elkins W, Rose J, Honings D, et al. Rapid and selective cerebral hypothermia achieved using a cooling helmet. J Neurosurg 2004;100:272-277.

93. Milhaud D, Thouvenot E, Heroum C, Escuret E. Prolonged moderate hypothermia in massive hemispheric infarction: clinical experience. J Neurosurg Anesthesiol 2005;17:49-53.

94. Lyden PD, Allgren RL, Ng K, Akins P, Meyer B, Al-Sanani F, et al. Intravascular Cooling in the Treatment of Stroke (IC$\mathrm{TuS}$ ): early clinical experience. J Stroke Cerebrovasc Dis 2005; 14:107-114.

95. Els T, Oehm E, Voigt S, Klisch J, Hetzel A, Kassubek J. Safety and therapeutical benefit of hemicraniectomy combined with mild hypothermia in comparison with hemicraniectomy alone in patients with malignant ischemic stroke. Cerebrovasc Dis 2006;21:79-85.

96. Guluma KZ, Hemmen TM, Olsen SE, Rapp KS, Lyden PD. A trial of therapeutic hypothermia via endovascular approach in awake patients with acute ischemic stroke: methodology.
Acad Emerg Med 2006; 13:820-827.

97. Martin-Schild S, Hallevi H, Shaltoni H, Barreto AD, Gonzales NR, Aronowski J, et al. Combined neuroprotective modalities coupled with thrombolysis in acute ischemic stroke: a pilot study of caffeinol and mild hypothermia. J Stroke Cerebrovasc Dis 2009; 18:86-96.

98. Hemmen TM, Raman R, Guluma KZ, Meyer BC, Gomes JA, Cruz-Flores $\mathrm{S}$, et al. Intravenous thrombolysis plus hypothermia for acute treatment of ischemic stroke (ICTuS-L): final results. Stroke 2010;41:2265-2270.

99. Bi M, Ma Q, Zhang S, Li J, Zhang Y, Lin L, et al. Local mild hypothermia with thrombolysis for acute ischemic stroke within a 6-h window. Clin Neurol Neurosurg 2011;113:768-773.

100. Abou-Chebl A, Sung G, Barbut D, Torbey M. Local brain temperature reduction through intranasal cooling with the RhinoChill device: preliminary safety data in brain-injured patients. Stroke 2011;42:2164-2169.

101. Mourand I, Escuret E, Heroum C, Jonquet O, Picot MC, Mercier $\mathrm{G}$, et al. Feasibility of hypothermia beyond 3 weeks in severe ischemic stroke: an open pilot study using gamma-hydroxybutyrate. J Neurol Sci 2012;316:104-107.

102. Ovesen C, Brizzi M, Pott FC, Thorsen-Meyer HC, Karlsson T, Ersson A, et al. Feasibility of endovascular and surface cooling strategies in acute stroke. Acta Neurol Scand 2013;127:399405.

103. Piironen K, Tiainen M, Mustanoja S, Kaukonen KM, Meretoja A, Tatlisumak T, et al. Mild hypothermia after intravenous thrombolysis in patients with acute stroke: a randomized controlled trial. Stroke 2014;45:486-491. 